\title{
Beneficial effects of rosemary, thyme and tarragon essential oils on postharvest decay of Valencia oranges
}

\author{
Mojgan Bakhtiarizade ${ }^{1}$ and Mohammad Kazem Souri ${ }^{2^{*}}$
}

\begin{abstract}
Background: Increasing restrictions on pesticide application in the production process of agricultural food products indicate urgent need for safer alternatives to keep the product quality, and to inhibit pathogen infections. In the present study, effect of three essential oils from rosemary, thyme and tarragon, in concentrations of 500 and 1000 ppm, were evaluated on shelf life and postharvest decay of Valencia oranges and under laboratory conditions. Valencia fruits were inoculated with or without crushing the fruit peel surface with the blue mold fungi (Penicillium italicum). The extent of decay and some quality parameters were evaluated during 4 weeks.

Results: When inoculation was performed with peel surface crushing, all fruits were fully decayed after 1 week, and only fruits in control (without infection) remained intact. However, when fruits were inoculated by just submerging and without peel crushing, depending on applied oil sources and oil concentrations, significant reduction in fruit decay was observed. Tarragon and thyme essential oils in both concentrations reduced the fruit decay; however, their 1000 ppm rather than 500 ppm was more effective on preventing fruit decay. Rosemary essential oil was less effective than the other two essential oils on preventing orange decay by blue mold fungi.
\end{abstract}

Conclusions: Tarragon and then thyme oils were most effective on preventing fruit decay and can be effectively used during postharvest handling and storage to keep Valencia orange fruits out of decaying.

Keywords: Citrus fruits, Blue mold, Bioactive compounds, Disease control, Quality, Medicinal plants

\section{Introduction}

Plant essential oils represent an alternative to pesticide application in the production processes of agricultural foods. The literature indicates the efficient records of essential oils on postharvest quality of many crops [5, 19]. Citrus fruits are vulnerable to mechanical injury at postharvest and handling, which accelerates their decay by various fungi $[6,21]$. Blue mold fungi (Penicillium italicum Wehmer) are one of the main decay agents of all citrus fruits [6]. Different chemicals and pesticides are generally used to control such postharvest diseases; however, the pesticides-resistant accessions are simply arisen among the fungi [11].

\footnotetext{
*Correspondence: mk.souri@modares.ac.ir

2 Dept of Horticultural Sciences, Tarbiat Modares Uni., Tehran, Iran

Full list of author information is available at the end of the article
}

Since the ancient times, various natural compounds have been used to control plant diseases and to prevent product losses due to microbial effects [13, 14]. Plantbased products are safe substances and good candidates for control of disease and pests, and nowadays some of them are available that could effectively suppress pathogenic infections in agriculture products $[15,16]$. The demand for food products free of pesticides and chemicals is growing.

It has been shown that application of plant essential oils or plant extracts can effectively control many plant pathogens particularly postharvest infections ([2, 3, 6 19], Plaza et al. 2015). Plant essential oils have antifungal and antibacterial effects, and these effects vary based on plant species and applied oil concentrations $[2,6,10$, $17,25]$. Plant essential oils can play role in control of fruit 
decay induced by Botrytis cinerea, Penicillium italicum, Phytophtora citrophthora, Rhizopus stolonifer and by Aspergillus spp. [2, 6, 8, 20]. Essential oils from oregano, lavendula, thyme, rosemary and fennel plants significantly prevented the blight disease of Phytophthora on tomato plants [25].

In an experiment by Camele et al. [6], 12 essential oils from various aromatic herbs of Mediterranean region were used in different concentrations against postharvest diseases of citrus fruits including $B$. cinerea, $P$. italicum, $P$. citrophthora and $R$. stolonifer, and only three of them were effective to prevent disease infection [6]. In addition, various studies revealed that application of natural plant-based essential oils are effective on prevention of both mycelium growth and spore germination of many fungal pathogens $[6$, 18, 20, 25]. Peppermint and sweet basil essential oils have shown promising fumigation controlling against fungal diseases, and essential oils from Ocimum sanctum, Prunus persica, Zingiber officinale were effective against gray decay in various plants [27]. Essential oils from areal parts of oregano, thyme, lavendula, rosemary and fennel at different concentrations were found to reduce blight infection of tomato, the most effective were the oils from thyme and oregano plants [25]. In a study using six essential oils from different plant species, it was shown that garlic essential oil had complete inhibition on eight various fungal diseases under laboratory conditions [17]. Many studies indicate the effectiveness of essential oils and plant extracts of clove, thyme, bay, basil, Angelica, calamus, citronella, lime and palmarosa on fungal and bacterial diseases [17, 18].

Oranges are generally very susceptible to decay during postharvest, and application of chemicals and fungicides could face consumer with health risk. Plant essential oils can significantly reduce postharvest decay of fruits. The effects of rosemary, tarragon and thyme oils have not been yet studied on Valencia orange fruit decay. So, in the present study essential oil from these three different aromatic plants were used and evaluated for their possible preventing effects on infection and growth of blue decay fungi of Valencia oranges.

\section{Materials and methods}

\section{Plant material}

This study was done under laboratory conditions at Tarbiat Modares Uni., Tehran-Iran. Valencia fruits were collected from a field in Jiroft (Kerman province) as a main area for citrus growing in southeast of Iran. The fruits were then immediately transferred to laboratory and those with uniform size and appearance were further selected for treatment applications.

\section{Inoculation and infection process}

Fruits were first disinfected using $10 \%$ hypochlorite solution for $5 \mathrm{~min}$, and then were washed using tap water and very gently were dewatered using a thin-layered filter paper. Inoculant source was prepared from contaminated fruits after homogenized in distilled water at $20{ }^{\circ} \mathrm{C}$. The suspension was passed through a filter paper, and an aliquot of the filtrate was transferred to various bowls for infection of fruits. The concentration of spores was equal in all bowls.

In the first experiment, fruit peel was crushed (about $1 \mathrm{~mm}$ depth) on two sides, using a sharp-tip pin, which was infected with inoculant suspension solution. Inoculated fruits were allowed for $24 \mathrm{~h}$ at $20{ }^{\circ} \mathrm{C}$ and relative humidity of $85 \%$ to fix the disease agent in crushed points.

In the second experiment, orange fruits were treated without crushing, and only by emerging in inoculant suspension for $1 \mathrm{~min}$. Then, inoculated fruits were allowed to fix disease agent for $24 \mathrm{~h}$. The temperature was maintained at $20^{\circ} \mathrm{C}$ with relative humidity $85 \%$, similar to the first experiment. The decaying intensity and the overall decayed fruits were recorded at the end of each respected week. The decaying level of fruits was also categorized as fruits with no decay (intact fruits), those fruits with partial decay, fruits with half decayed, and those fully decayed fruits.

\section{Treatment application}

After inoculation with spores of blue mold fungi (Penicillium italicum Wehmer), fruits were treated using different concentrations of essential oils of rosemary (Rosmarinus officinalis L.), thyme (Thymus vulgaris) and tarragon (Artemisia dracunculus). Pure essential oils (in liquid form) were purchased from market (Zardband Company, Tehran-Iran), and their corresponding concentrations of 0,500 and $1000 \mathrm{ppm}$ were prepared in distilled water. For this purpose, the essential oils were dissolved in $1 \mathrm{~mL}$ ethanol (75\%) and then distilled water was added to reach the corresponding concentrations of $500 \mathrm{ppm}$ and $1000 \mathrm{ppm}$ of each essential oil. These concentrations were prepared in a $0.5-\mathrm{L}$ bowl and fruits of each treatment were flooded/submerged for $2 \mathrm{~h}$ and then were allowed to dryness (for $20 \mathrm{~min}$ ) at room temperature of $20 \pm 3^{\circ} \mathrm{C}$. The zero concentration was regarded as control.

Two control treatments were used; the first series as control 1 were those fruits without any treatment (without infection and without essential oil treatments, negative control). The second series as control 2 were those fruits that inoculated with blue decay fungi inoculants, but received no essential oil or other curing treatments, positive control. The fruits in both series of controls and 
in the main treatments were kept under same laboratory conditions. The temperature during 4 weeks of storage was $20 \pm 3{ }^{\circ} \mathrm{C}$, and the air relative humidity was in range of $75-85 \%$ during the course of experiment. The experiment was arranged in completely randomized design with three replications, each consisted of three fruits. After applying the treatments, fruits of each replication were transferred to plastic baskets and after determination of their original weight, they were transferred to experimental room with specific conditions $\left(20 \pm 3{ }^{\circ} \mathrm{C}\right.$ temperature, $75-85 \%$ relative humidity).

\section{Measurements}

Total soluble solids (TSS), vitamin C content, fruit juice $\mathrm{pH}$ and total acids of fruits were determined at the end of 2nd week, when still significant intact fruits were remained for all treatments. The percentage of intact fruits as well as the percent of decayed fruits were recorded at the end of each respective week up to 4 weeks. The average weight of three fruits in each replication was recorded before and after the experiment, using a precise balance. The rate of fruit weight loss and fruit decay percentage was recorded. Total soluble solids (TSS) of fruits were measured by a portable Refractometer (Atago model Tokyo, Japan), and total acids of fruits were measured and calculated based on citric acid and using titration by $\mathrm{NaOH} 0.1 \mathrm{~N}$ until reaching the target $\mathrm{pH}$ of 8.1 following Souri and Aslani [22]. For the determination of fruit vitamin C, $50 \mathrm{~g}$ of fresh fruit slices was crushed and squeezed by a hand squeezer in vicinity of $10 \mathrm{~mL}$ metaphosphoric acid 6\%, and then the juice was transferred into a $25-\mathrm{mL}$ tube, then centrifuged at $4000 \mathrm{rpm}$ for $10 \mathrm{~min}$. Five milliliters of the supernatant was transferred into an Erlenmeyer flask, and $20 \mathrm{~mL}$ of metaphosphoric acid $3 \%$ was added. The titration of the extract was done by 2,6-di-chloro phenol indophenols until appearance of a rosa color, which the amount of vitamin C (mg $100 \mathrm{~g}^{-1} \mathrm{FW}$ ) was calculated accordingly and based on a standard curve of different $\mathrm{L}$-ascorbic acid concentrations according to Souri and Aslani [22].

\section{Essential oil analysis}

The essential oils were analyzed using GC-MC apparatus. The analysis was performed on a Varian CP-3800 GC coupled with Varian 4000 (Ion trap) Mass system. The carrier gas was helium and mass spectra were taken at $70 \mathrm{eV}$. Mass range was from $\mathrm{m} / \mathrm{z} 35$ to 400 amu. Identification of each individual constituent of the essential oil was achieved based on their retention indices and following Ghanbari et al. [13]. The compounds were identified by comparison of their mass spectra with those of the internal reference mass spectra library or with authentic compounds and confirmed by comparison of their retention indices with authentic compounds or with those reported in the literature. For quantification purpose, relative area percentages obtained by FID were used without the use of correction factors.

\section{Statistical analysis}

Data were analyzed by SPSS 16 software, and comparison of means was done at $5 \%$ level of Duncan's multiple range test.

\section{Results}

In the first experiment, when fruit inoculation was done using peel crushing, the essential oils of three herbs in their two concentrations of 500 and $1000 \mathrm{ppm}$ were not effective to prevent decaying progress (data not shown). So, at the end of 1st week, similar to fruits in control 2, all fruits were decayed.

In the second experiment, when inoculation was done using fruit submerging without crushing, the results showed that the oils and their corresponding concentrations were effective in preventing the Valencia orange fruit decay (Tables 1, 2 and 3).

The percentage of intact fruits without decay symptoms during 4 weeks is presented in Table 1 . The results (Tables 1,2) show that application of $500 \mathrm{ppm}$ rosemary oil was not effective on reducing fruit decay progress; however, it was partially effective on preventing fruit decay only when $1000 \mathrm{ppm}$ rather than $500 \mathrm{ppm}$ was applied. The oil from thyme was effective in both concentrations; however, higher concentration of 1000 rather than $500 \mathrm{ppm}$ was more effective to prevent fruit decay. Tarragon oil was the most effective among three oils, particularly in $1000 \mathrm{ppm}$ concentration (Tables 1, 2). The fruits treated with rosemary oil were the first to be decayed and those fruits treated with tarragon oil were decayed the last. After 2 weeks, only thyme and tarragon oils at higher concentration of $1000 \mathrm{ppm}$ were fully effective on reduction of blue mold decay (Table 1). At the end of 3rd week and 4th week, all inoculated fruits were decayed and only some fruits in negative control were intact (Table 1).

The decay intensity of fruits at the end of 1st, 2nd and 3rd week is presented (Table 2). For each presented date, the fruit decay intensity in treatments was as following: positive control $>$ rosemary $500>$ rosemary $1000>$ thyme $500>\operatorname{tarragon} 500>$ thyme $1000>$ tarragon $1000>$ negative control.

Determination of fruit quality characteristics (Table 3) showed that there was no significant difference among treatments for fruit juice $\mathrm{pH}$ among treatments (data not 
shown). Total acids were significantly highest in fruits of control 1 and those inoculated fruits that were treated with $1000 \mathrm{ppm}$ tarragon oil. The least total acids of fruits were recorded in $500 \mathrm{ppm}$ rosemary oil treatment. The significant maximum vitamin $C$ content was recorded in fruits in control 1, thyme oil at $1000 \mathrm{ppm}$ and tarragon oil at $1000 \mathrm{ppm}$ treatments. The least amount of vitamin C was recorded in control 2 and in fruits treated with both concentration of rosemary oil. The significant maximum TSS was obtained in fruits in control 1 and fruits treated with $1000 \mathrm{ppm}$ tarragon oil, while the least TSS was obtained in control 2 and 1000 ppm rosemary oil treatment (Table 3).

Results showed that the weight loss was increased by inoculation treatment and decaying intensity of fruits (Fig. 1). The highest weight loss was recorded in fruits in control 2, and in fruits treated with 500 ppm rosemary oil and both concentration of thyme oil. Fruits in control 1, as well as those treated with $1000 \mathrm{mg} \mathrm{L}^{-1}$ of tarragon and thyme oils showed the least fruit weight loss.

The analysis of essential oils of these three sources shows that the oils are composed of various compounds (Table 4).

\section{Discussion}

In the present study, when Valencia fruits were inoculated with crushing, they were rapidly decayed during 1 week, regardless of oil sources and concentrations (data not shown). Valencia fruits are rather resistant to decaying if they are harvested and stored in proper conditions; however, over their damage or crushing, they are decayed very rapidly [21]. It seems that the speed of disease growth was high, as none of plant's oil and dosages were effective to reduce the fungal infection rates. This indicates that the penetrating rates of oils and fungi into fruit tissues might be different, which can be a limiting factor in the application of essential oil for such purposes. Different antifungal and antibacterial effects of essential oils under in vitro and in vivo conditions confirm this speculation $[2,7,12,15]$. It has been shown that thyme, oregano, clove and cinnamon essential oils completely inhibited Penicillium digitatum and P. italicum growth either when added into the medium at $1000 \mu \mathrm{L} \mathrm{L}^{-1}$ or by their volatiles with $10 \mu \mathrm{L}$ per 5 -cm-diameter Petri dish. However, similar to our results, in in vivo experiments, none of the oils tested effectively reduced the incidence of $P$. digitatum and $P$. italicum on oranges after being applied directly over the inoculated wound at 10, 100 or $1000 \mu \mathrm{L} \mathrm{L}^{-1}$ [21].

In the second experiment, when fruits were inoculated without peel crushing (by submerging), significant prevention of fruit decay was achieved by oil treatments. Our data indicate that the protective role of fruit peel is very important. This role could be due to the physicochemical properties of fruit peels, as orange peel has a wide range of bioactive compounds $[23,26]$ including essential oils and alcohols, which could probably have a synergetic effect on applied essential oils in the present study.

The highest number of intact fruits and the lowest fruit weight loss were in control 1 and in those fruits treated with tarragon and thyme oils at $1000 \mathrm{ppm}$, while both concentrations of rosemary and the first level of thyme and tarragon oils were not very effective. Similarly, it has been shown that oils characterized by high concentrations of S-carvone were less effective than those containing the R-enantiomer [8]. In another study, using essential oils from 12 Mediterranean aromatic plants, only 3 of them were effective to suppress various postharvest diseases of citruses [6]. Effectiveness of different essential oils on preventing the growth of plant pathogens has been well established [3, 10, 23, 20,27]. The oils of thyme $(500 \mathrm{ppm})$ and vervain $(1000 \mathrm{ppm})$ were significantly reduced several peach fruit postharvest decay [12]. On the other hand, thyme oil was the most effective from 18 essential oils tested against five pathogens

Table 1 The percentage (\%) of intact (not decayed) fruits when fruits were surface inoculated with blue mold fungi

\begin{tabular}{lllll}
\hline & After $\mathbf{1}$ week & After 2 weeks & After 3 weeks & After $\mathbf{4}$ weeks \\
\hline Negative control & 100 & 100 & 90 & 55 \\
Positive control & 0 & 0 & 0 & 0 \\
Ros500 & 0 & 0 & 0 & 0 \\
Ros1000 & 11.1 & 0 & 0 & 0 \\
Thym500 & 22.2 & 0 & 0 & 0 \\
Thym1000 & 44.4 & 11.1 & 0 & 0 \\
Tar500 & 22.2 & 0 & 0 & 0 \\
Tar1000 & 55.5 & 33.3 & 0
\end{tabular}

Ros, Thyme and Tar are abbreviations for rosemary, thyme and tarragon plants that their essential oil was used in two concentrations of 500 and 1000 ppm in this study 


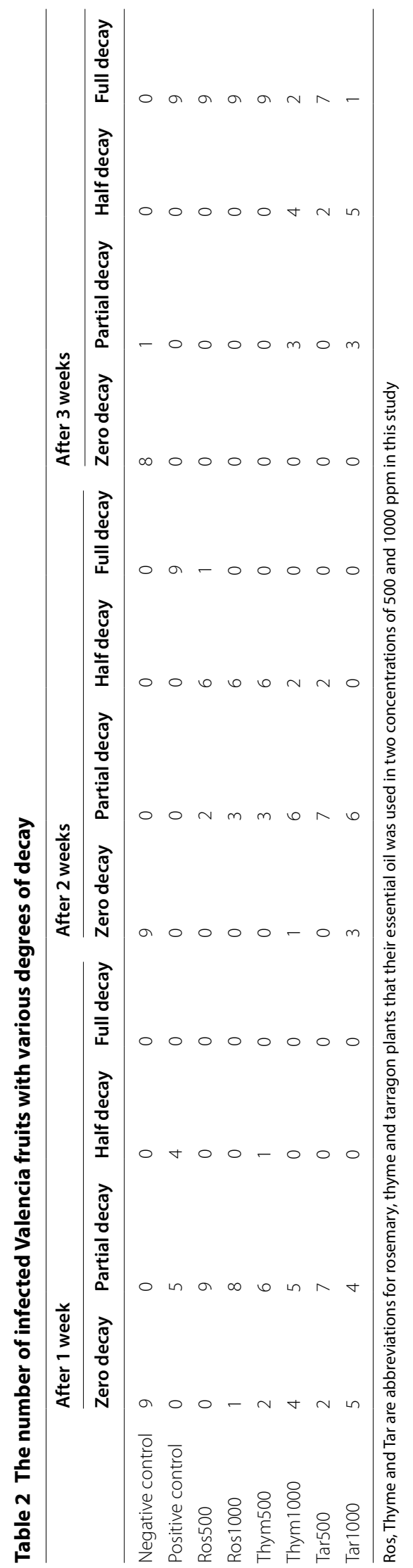


Table 3 Total acids, vitamin C concentration, fruit juice pH and total soluble solids of fruits under various treatments at the end of 2 nd week

\begin{tabular}{llll}
\hline & Total acids (\%) & $\begin{array}{l}\text { Vitamin C } \\
\mathbf{( m g / 1 0 0 ~} \mathbf{~ F W})\end{array}$ & TSS (\%) \\
\hline Negative control & $1.31 \mathrm{a}$ & $152.5 \mathrm{a}$ & $13.7 \mathrm{a}$ \\
Positive control & $1.19 \mathrm{ab}$ & $92.1 \mathrm{c}$ & $11.7 \mathrm{~b}$ \\
Ros500 & $1.17 \mathrm{~b}$ & $96.4 \mathrm{c}$ & $12.0 \mathrm{ab}$ \\
Ros1000 & $1.24 \mathrm{ab}$ & $97.2 \mathrm{c}$ & $11.7 \mathrm{~b}$ \\
Thym500 & $1.22 \mathrm{ab}$ & $112.6 \mathrm{~b}$ & $12.7 \mathrm{ab}$ \\
Thym1000 & $1.28 \mathrm{ab}$ & $147.3 \mathrm{a}$ & $13.3 \mathrm{ab}$ \\
Tar500 & $1.20 \mathrm{ab}$ & $115.9 \mathrm{~b}$ & $12.7 \mathrm{ab}$ \\
Tar1000 & $1.31 \mathrm{a}$ & $149.4 \mathrm{a}$ & $13.7 \mathrm{a}$ \\
\hline
\end{tabular}

Ros, Thyme and Tar are abbreviations for rosemary, thyme and tarragon plants that their essential oil was used in two concentrations of 500 and 1000 ppm in this study

Different letters in each column are statistically different (Duncan's multiple range test)

(Lasiodiplodia theobromae, Colletotrichum gloeosporioides, Alternaria citri, B. cinerea and P. digitatum) under in vitro conditions [8].

The essential oils of various plants including Mentha arvensis, Ocimum canum and $Z$. officinale were effective against Penicillium italicum fungi. Mint extract was effective on prevention of blue mold infection on postharvest of orange and lemon fruits that resulted in longer storage ability of 6-7 days. However, using zingiber essential oil, the shelf life of orange and lemon was improved by 4 and 8 days [26]. The volatile phases of oregano and thyme in $0.3 \mu \mathrm{g} \mathrm{mL}{ }^{-1}$ concentration were the most effective, which completely prevented the growth of disease blight disease of phytophthora on tomato plants [25]. Full prevention by other essential oils (lavendula, rosemary and fennel) was obtained at $0.4-2 \mu \mathrm{g} \mathrm{mL} \mathrm{m}^{-1}$ [25].

Although in the present study oil from rosemary had the least effect on blue mold decay of fruits; however, the effectiveness of rosemary oil on various microbial activities on food stuffs [2] as well as its biostimulation effect of seedling growth have been well demonstrated [24].

Postharvest quality of fruits was also influenced by oil treatments in our study. Postharvest decay of strawberries was also controlled using different concentrations of cumin essential oil. The fruit firmness and the amount of soluble solids were not affected by cumin essential oil, while total acids, fruit juice $\mathrm{pH}$ and vitamin $\mathrm{C}$ content were influenced by oil treatments [3]. Similar effects were also obtained on tomato blight infection with thyme and oregano oils [25].

Different compounds including alcohols, aldehydes, fatty acids derivatives, terpenoides and phenols are generally present in essential oil in various plant species [9, 15]. Many bioactive effects of plant essential oils are due to antioxidant properties of these oil components, which probably in combination induce antimicrobial effects. It has been shown that essential oil from two thyme species inhibits the growth and morphology of fungi mainly due to disturbing the enzymatic activity of fungal cells [18]. So, nowadays, thyme essential oil is used as a protective compound in many food products [4].

Essential oils are safe and effective alternatives to synthetic pesticides $[14,15]$. Green plants and their natural products represent effective biological agents with antibiotic effects that are less toxic and more biodegradable

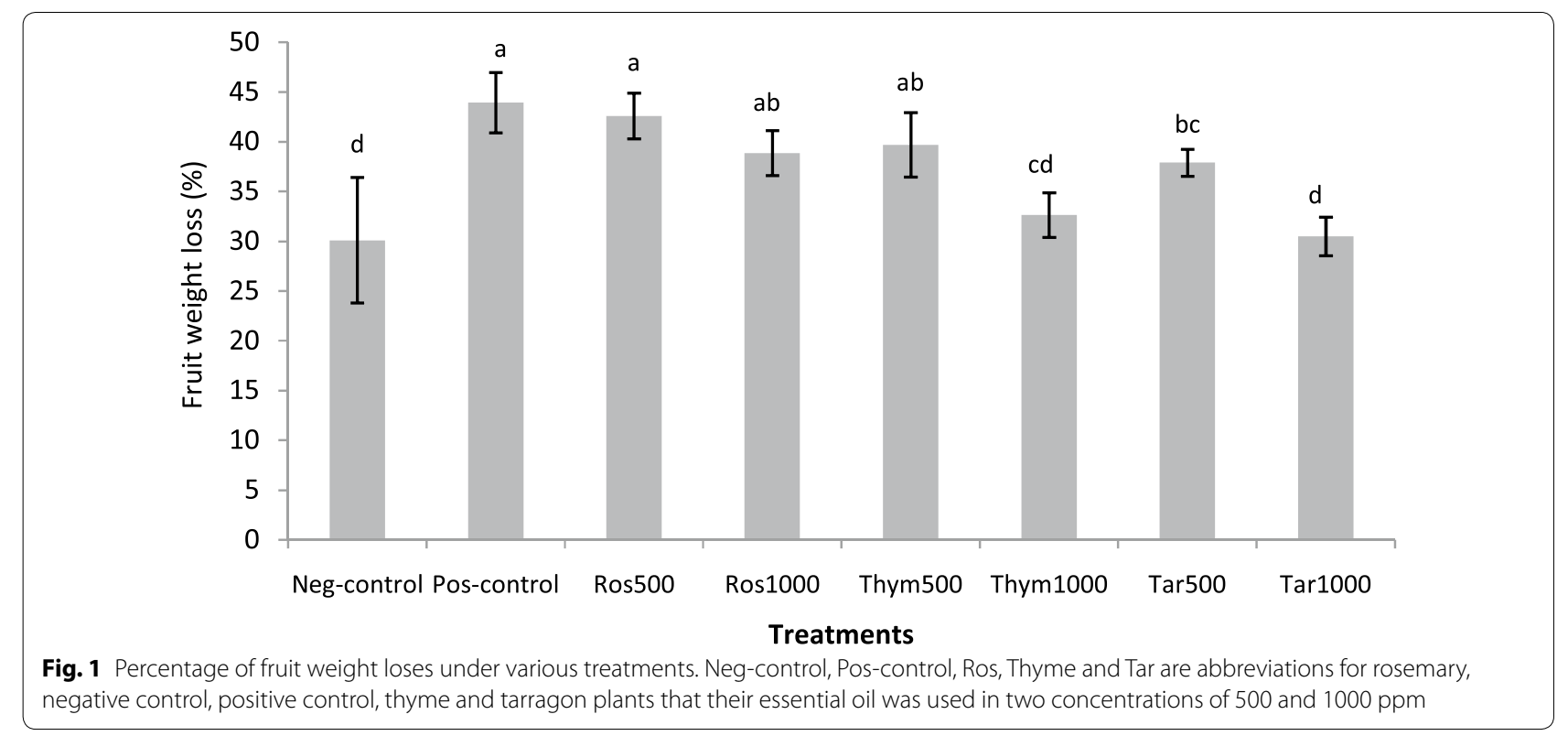


Table 4 Composition of the essential oils of three sources

\begin{tabular}{|c|c|c|c|c|c|}
\hline Tyme essential oil & & Tarragon essential oil & & Rosemary essential oil & \\
\hline Thymol & $53 \%$ & Methyl chavicol & $83 \%$ & 1,8-Cineole & $49.7 \%$ \\
\hline Para-cymene & $13.3 \%$ & Trans-ocimene & $4.5 \%$ & a-Pinene & $13.2 \%$ \\
\hline Gamma-terpinene & $12.5 \%$ & Limonene & $4.3 \%$ & Camphor & $7.4 \%$ \\
\hline Carvacrol & $9.8 \%$ & Methyl eugenol & $4.1 \%$ & $\beta$-Pinene & $5.2 \%$ \\
\hline Linalool & $2 \%$ & Alpha-pinene & $1.6 \%$ & Camphene & $5.4 \%$ \\
\hline 1.8-Cineol & $1.4 \%$ & Unknown compounds & $7 \%$ & Borneol & $4.6 \%$ \\
\hline Myrcene & $1.5 \%$ & & & a-Terpineol & $2.1 \%$ \\
\hline Terpinolene & $1.4 \%$ & & & Myrcene & $2.8 \%$ \\
\hline Alpha-thujene & $1.3 \%$ & & & Unknown compounds & $9.5 \%$ \\
\hline Unknown compounds & $3 \%$ & & & & \\
\hline
\end{tabular}

[24]. They have higher systemic effects with high toxicity against a wide range of fungal and bacterial pathogens $[5,19]$. The main advantage of plant essential oils is their biological activity in gaseous phase which represents them as excellent fumigant for control of storage decays $[26,27]$ and for repelling of many insects [14, 15, 27]. Nevertheless, solubility in water, their volatile nature, and sometimes required high concentrations for such preventing effects are seen as real limitation to their practical application.

The essential oils of these three sources are composed of various compounds and their antimicrobial activity cannot be confirmed based only on the action of one compound $[4,10]$. The major constitute of oil from tarragon (methyl chavicol 83\%), thyme (thymol 53\%) and rosemary (1,8-cineole $49.7 \%)$ may contribute in the preventing effects observed in this study. In fact, the thyme oil is characterized by the high percentage of phenolic precursors (thymol, p-cymene and o-cymene) and phenolic compounds [7].

The antimicrobial action of these essential oils (tarragon and theme oils) may be attributed to their ability to penetrate through microbial membranes to the interior of the cell and exhibit inhibitory activity on the functional properties of the cell, and to their lipophilic properties [1, $4,19]$. The mechanisms of action may relate to the ability of different components of their oils to alter microbial cell permeability, damage cytoplasmic membranes, interfere with cellular energy generation system, and disrupt the proton motive force $[1,4]$.

\section{Conclusion}

In this study, when orange fruits were inoculated by submerging rather than by crushing, significant inhibition effects of essential oils were observed on blue mold decay. The essential oil of tarragon and thyme particularly at $1000 \mathrm{ppm}$ effectively reduced the postharvest infection rate of blue decay of orange fruits. Essential oils from these plants are simply accessible and can be obtained or purchased in much lower cost than expensive unsafe synthetic fungicides. Food safety is very important particularly in fresh fruits and vegetables. So, essential oils represent very safer and effective natural products for control of postharvest pathogenic infections of Valencia oranges, and probably in other citrus products.

\section{Abbreviations}

ppm: parts per million; TSS: total soluble solids; FW: fresh weight; Neg-control: negative control; Pos-control: positive control; Ros: rosemary; Thyme: thymus; Tar: tarragon.

\section{Authors' contributions}

MKS designed the experiment and analyzed the data and wrote the manuscript, MB conducted the laboratory measurements. Both authors read and approved the final manuscript.

\section{Author details \\ ${ }^{1}$ Dept of Horticulture, Azad Uni. of Jiroft, Jiroft, Iran. ${ }^{2}$ Dept of Horticultural \\ Sciences, Tarbiat Modares Uni., Tehran, Iran.}

\section{Acknowledgements}

We give our special thanks to Prof. Dr. Arzani, the head of Dept. of Horticultural Sciences at Tarbiat Modares University for their supporting of required chemicals and instruments for conducting this study.

\section{Competing interests}

The authors declare that they have no competing interests.

Availability of data and materials Not applicable.

Consent for publication

We declare our agreement.

Ethics approval and consent to participate

All authors contributed in design and preparation of the research, and they have read the final version of the manuscript.

\section{Funding}

Not applicable. 


\section{Publisher's Note}

Springer Nature remains neutral with regard to jurisdictional claims in published maps and institutional affiliations.

Received: 20 November 2018 Accepted: 11 February 2019

Published online: 25 April 2019

\section{References}

1. Antunes MDC, Cavaco AM. The use of essential oils for postharvest decay control. A review. Flavour Fragr J. 2010;25(5):351-66.

2. Arras G, Usai M. Fungitoxic activity of twelve essential oils against four postharvest Citrus pathogens: chemical analysis of Thymus capitatus (L.) oil and its effect in subatmospheric pressure conditions. J Food Prot. 2001;64:1025-9.

3. Asghari Marjanlo A, Mostofi Y, Shoeibi S, Fattahi M. Effect of cumin essential oil on postharvest decay and some quality factors of strawberry. J Med Plants. 2009:8:36-43.

4. Bajpai VK, Baek KH, Kang SC. Control of Salmonella in foods by using essential oils: a review. Food Res Int. 2012;45:722-34.

5. Calo JR, Crandall PG, O'Bryan CA, Ricke SC. Essential oils as antimicrobials in food systems - a review. Food Control. 2015;54:111-9.

6. Camele I, De Feo V, Altieri I, Mancini E, De Martino L, Luiqi Rana G. An attempt of postharvest orange fruit rot control using essential oils from Mediterranean plants. J Med Food. 2010;23:45-52.

7. Cheurfa M, Allem R, Sebaihia M, Belhireche S. Effect of essential oil of Thymus vulgaris on bacterial pathogens responsible for gastroenteritis. Phytotherapie. 2013;11:154-60.

8. Combrinck S, Regnier T, Kamatou GPP. In vitro activity of eighteen essential oils and some major components against common postharvest fungal pathogens of fruit. Ind Crops Prod. 2011;33(2):344-9.

9. Couladis M, Tzakou O, Kujundzic S, Sokovic M, Mimica-Dukic N. Chemical analysis and antifungal activity of Thymus striatus. Phytother Res. 2004;18:40-2.

10. Delaquis PJ, Stanich K, Girard B, Mazza G. Antimicrobial activity of individual and mixed fractions of dill, cilantro, coriander and eucalyptus essential oils. Int J Food Microbiol. 2002;74:101-9.

11. Eckert JW. Postharvest disease control: experience with citrus fruit. Tree Fruit Postharvest J. 1995;6:9-12.

12. Elshafie HS, Mancini E, Camele I, De Martino L, De Feo V. In vivo antifungal activity of two essential oils from Mediterranean plants against postharvest brown rot disease of peach fruit. Ind Crops Prod. 2015:66:11-5.

13. Ghanbari M, Souri MK, Mirzaei HH, Omidbaigi R. The essential oils composition in two populations of Achillea wilhelmsii C. Koch from Iran. Zeitschrift fur Arznei-und Gewurzpflanzen. 2016;21(3):107-10.
14. Heidarpour O, Souri MK, Omidbaigi R. Changes in content and constituents of essential oil in different plant parts of Lovage (Levisticum officinale Koch. Cv. Budakalaszi) cultivated in Iran. J Essent Oil Bear Plants. 2013;16(3):318-22.

15. Isman MB. Plant essential oils for pest and disease management. Crop Prot. 2000;19:603-8

16. Isman MB, Machial CM. Pesticides based on plant essential oils: from traditional practice to commercialization. Adv Phytomedicine. 2006;3:29-44.

17. Lalitha V Kiran B, Ravesha KA. Antifungal and antibacterial potentiality of six essential oils extracted from plant source. Int J Eng Sci Technol. 2011;3:1029-3038.

18. Lee Y, Kim J, Shin S, Lee S, Park I. Antifungal activity of Myrtaceae essential oils and their components against three phytopathogenic fungi. Flavour Fragr J. 2008;23:23-8.

19. Mari M, Bautista-Baños S, Sivakumar D. Decay control in the postharvest system: role of microbial and plant volatile organic compounds. Postharvest Biol Technol. 2016;122:70-81.

20. Neri F, Mari M, Brigati S, Bertolini P. Fungicidal activity of plant volatiles compounds for controlling Monilinia laxa in stone fruit. Plant Dis. 2007:91:30-5

21. Plaza P, Torres R, Usall J, Lamarca N, Vinas I. Evaluation of the potential of commercial post-harvest application of essential oils to control citrus decay. J Hortic Sci Biotechnol. 2004;79(6):935-40.

22. Souri MK, Aslani M. Beneficial effects of foliar application of organic chelate fertilizers on French bean production under field conditions in a calcareous soil. Adv. Hort. Sci. 2018;32(2):265-72.

23. Regnier T, Du Plooy GW, Combrinck S, Botha BM. Fungitoxicity of Lippia scaberrima essential oil and selected terpenoid components on two mango postharvest spoilage pathogens. Postharvest Biol Technol. 2008;48:254-8

24. Souri MK, Bakhtiarizade M. Biostimulation effects of rosemary essential oil on growth and nutrient uptake of tomato seedlings. Sci Hortic. 2019:243:472-6.

25. Soylu EM, Soylu S, Kurt S. Antimicrobial activities of the essential oils of various plants against tomato late blight disease agent Phytophthora infestans. Mycopathologia. 2006;161:119-28.

26. Tripathi P, Dubey NK, Banerji R, Chansouria JPN. Evaluation of some essential oils as botanical fungitoxicants in management of post-harvest rotting of citrus fruits. World J Microbiol Biotechnol. 2004;20:317-21.

27. Ziedan EHE, Farrag ESH. Fumigation of peach fruits with essential oils to control postharvest decay. Res J Agric Biol Sci. 2008;4:512-9.

\section{Submit your manuscript to a SpringerOpen ${ }^{\circ}$ journal and benefit from:}

- Convenient online submission

- Rigorous peer review

- Open access: articles freely available online

- High visibility within the field

- Retaining the copyright to your article

Submit your next manuscript at springeropen.com 